\title{
Electrical Conductivity of Oxadiazole and Triazole Polymer Content
}

\author{
Aya Abdul-wahhab ${ }^{*}$, Assad F.Khattab ${ }^{2}$ \\ ${ }^{1 *}$ Chemistry Department, College of Science, University of Mosul, Mosul, Iraq \\ Email: ${ }^{*}$ Ayaabdalwahab2020@gmail.com, ${ }^{2}$ asaadfaisal@yahoo.com
}

(Received December 10, 2020; Accepted January 25, 2021; Available online June 01, 2021)

DOI: 10.33899/edusj.2021.129094.1131, () 2021, College of Education for Pure Science, University of Mosul.

This is an open access article under the CC BY 4.0 license (http://creativecommons.org/licenses/by/4.0/).

\begin{abstract}
:
Three types of oxadiazle and traizole monomers were prepared. The monomers are polymerized with different monomers to prepare eight different polymers. The polymers are differs in the type of bonding unit. The prepared polymers are identified by using infrared spectroscopy and elemental analysis. The prepared polymers are doped with different ratios of iodine and protonic acid $(\mathrm{HCl})$. The electrical conductivity of the pure and doped polymers was measured. Many different factors can effect on the conductivity of the polymers. The long flexible aliphatic moiety in the back bone of the polymer increase the electrical conductivity, while the presence of long aliphatic arm grafted as aside chain will decrease the conductivity. Also the type of the bonding group (amide or azomethin ) have a significant effect on the electrical conductivity. The study proved that the oxadiazole and triazole rings can participating in the conjugation of polymeric chain and enhanced the electrical conductivity. The nitrogen and oxygen atoms within the ring can participate with conjugation by their lone pair of electron and can be considered as a sites for doping. The electrical conductivity of the prepared polymers increased by increasing the ratio of the dopant but to limited percent. It was proved that the nitrogen atoms is more ready to protonated by acid than the oxygen atom.
\end{abstract}

Keywords: oxadiazole polymers, triazole polymers, electrical conductivity.

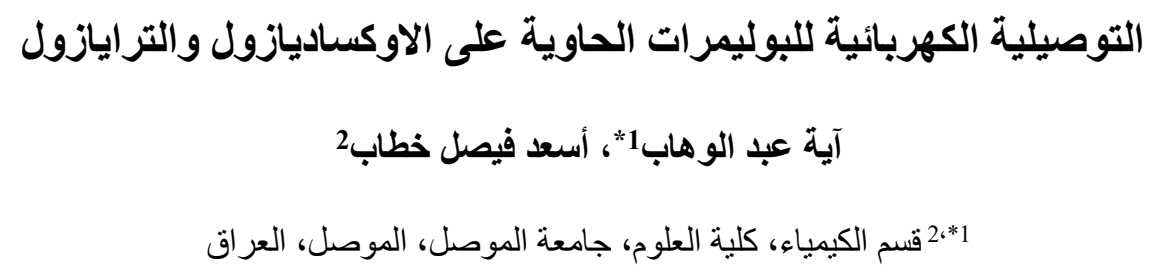

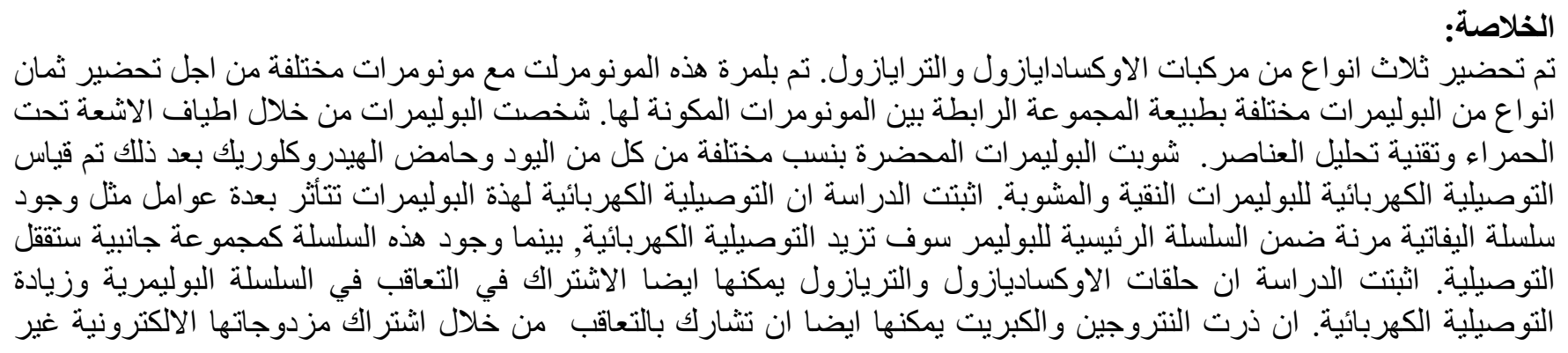




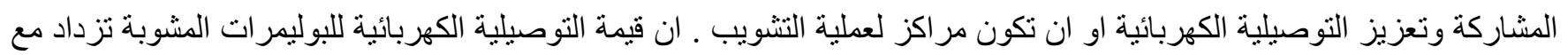

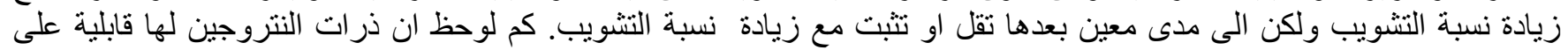

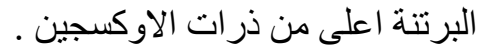

$$
\begin{aligned}
& \text { الكلمات المفتاحية: بوليمر ات الاوكساديازول ، بوليمرات الثرايازول ، التوصيلية الكهربائية. }
\end{aligned}
$$

\section{Introduction}

The field of electrically conducting polymers have been developed very rapidly since the discovery of intrinsically conducting polymers (1). It was noticed that the electrical conductivity of organic conjugated polymers was increased by many order of magnitude when they are doped with oxidizing or reducing agents (2).The doped polymers have been concept as an organic metal or semiconductors(3).The chemical structure of the conjugated polymers is confirmed of $\Pi$ electron system extending over long chain of monomer unit (4).This extending of $\Pi$ system gives the susceptibility of the oxidation and reduction with the electrical conductivity (5).

By controlling the oxidation or reduction processes, the electrical conductivity and optical properties of the polymer can be controlled(6). It is well known that the undoped conjugated polymers are established as intrinsic semiconductors(7). The value of the electrical conductivity is depend on the energy gap between HOMO and LUMO levels. Where by the energy gap in these type of polymers depend on the constitution of their backbone and on the nature of side substituents (8).

The presence of some heteroatoms within the carbon backbone conjugated polymers can enhanced the conjugated through the delocalization of their lone pair of electron with the conjugated system. On the other hand the heteroatoms $(\mathrm{N}, \mathrm{S}, \mathrm{O})$ provide sets for hosting the dopant molecules $(9)$. In the last decade , polymers containing heterocyclic ring can be considered as an electron donor or electron acceptor $(10,11)$. The electrical properties of the oxadiazole polymers was developed by loading the polymer on graphene nano sheet(12). The conjugated polymers that containing oxadiazole or triazole rings were used for building organic photovoltaic cells and their efficiency was enhanced by mixing the polymer with nano carbon tube(13).

In this work different polymers with oxadiazole and triazole heterocyclic ring have been prepared to prove the effects of chemical structure on the electrical conductivity. On the other hand the ability to doping was studied by different dopant.

\section{Experimental}

All the used chemicals were purchased from different original sources and used without purification .Terephthaloyl chloride was prepared by reflux $4 \mathrm{gm}$ of Terephthalic acid with $25 \mathrm{ml}$ of thionyl chloride in presence of few drops of DMF.

The infrared spectra of the prepared monomers and polymers have been recorded by using Infrared spectrometer Shimadzu (400-4000) $\mathrm{cm}^{-1}$.CHN elemental analysis were measured by using Veri OEL V5. The volume electrical conductivity measurements for the pure and doped polymers were performed by using lab made 3-probe de cell.

\section{Synthesis}

1,4-bis (1-hydrazineylvinyl)benzene (I):in a round bottom flask contain $20 \mathrm{ml}$ of hydrazine hydrate and $2 \mathrm{ml}$ dry dioxane, adding drop wise a solution of $6.5 \mathrm{~g}(0.03 \mathrm{~mole})$ of terephthaloyl chloride dissolved in $6 \mathrm{ml}$ dry dioxane at room temperature. The mixture was refluxed for extra $2 \mathrm{hrs}$. The yellow precipitate was filtered, washed with ethanol and dried under vacuum. 


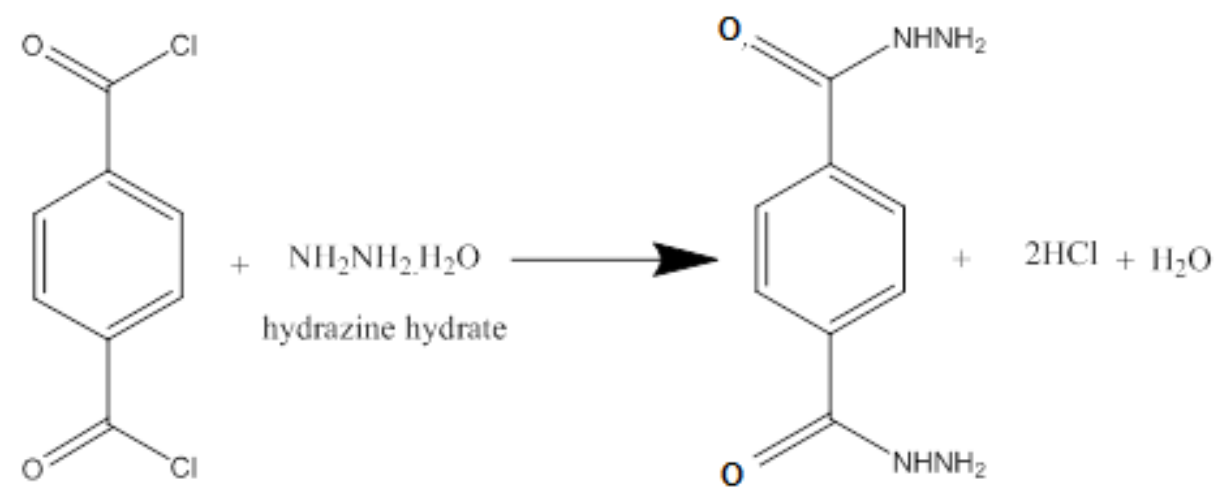

erephthaloyl dichloride

1,4-bis(1-hydrazineylvinyl)benzene (I)

5, '5-(1,4 phenylene)bis(1,3,4-oxadiazole-2-thiol) (M1):(REF)

$5.6 \mathrm{~g}(0.028 \mathrm{~mole})$ of I was dissolved in aqueous solution of $(1 \mathrm{M})$ sodium hydroxide and $60 \mathrm{ml}$ ethanol, $3.5 \mathrm{ml}$ of carbone disulfide was added drop wise at room temperature, refluxed the mixture for $30 \mathrm{~min}$. The excess ethanol was distilled out, the reaction mixture was cooled by crushed ice and acidified with $1 \mathrm{M} \mathrm{HCl}$ to $\mathrm{pH} 2$. The precipitate was filtered, washed with ethanol and dried under vacuum.

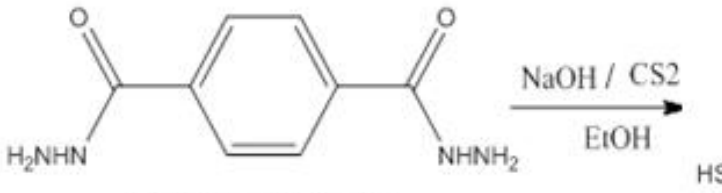

terephthalohydrazide

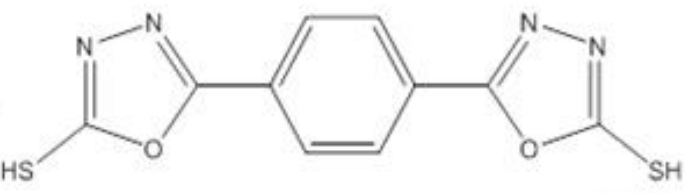

5.5'-(1.4-phenylene)bis(1,3,4-oxadiazole-2-thiol)

Triazol derivative of M1(M2):

$2.87 \mathrm{~g}(0.01 \mathrm{~mole})$ of M1 was refluxed with $20 \mathrm{ml}$ of hydrazine hydrate and $50 \mathrm{ml}$ of abs. ethanol for $8 \mathrm{hrs}$. the excess ethanol was distilled off, crushed ice was added to the reaction mixture and acidified with $1 \mathrm{M} \mathrm{HCl}$ to $\mathrm{PH} 2$. The product was filtered and washed with ethanol.

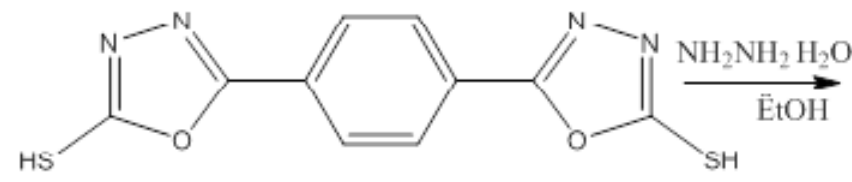

5,5'-(1,4-phenylene)bis( $1,3,4$-oxadiazole-2-thiol)

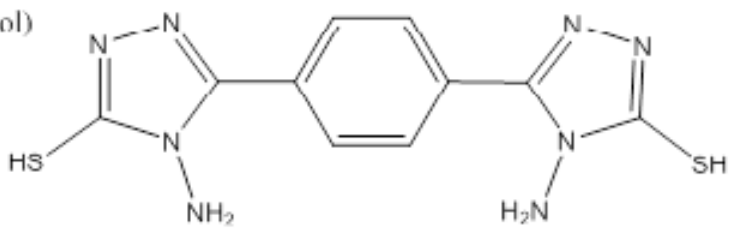

5,5'-(1,4-phenylene)bis(4-amino-4H-1,2,4-triazole-3-thiol) $\mathbf{M} 2$

\section{M3 Preparation}

$1.5 \mathrm{~g}(0.005 \mathrm{~mole})$ of M2 was dissolved in sodium hydroxide aqueous solution and refluxed with $0.7 \mathrm{ml}$ of 1-bromo hexane for $2 \mathrm{hrs}$.The product was filtered and washed with water and dried in vacuum oven. 


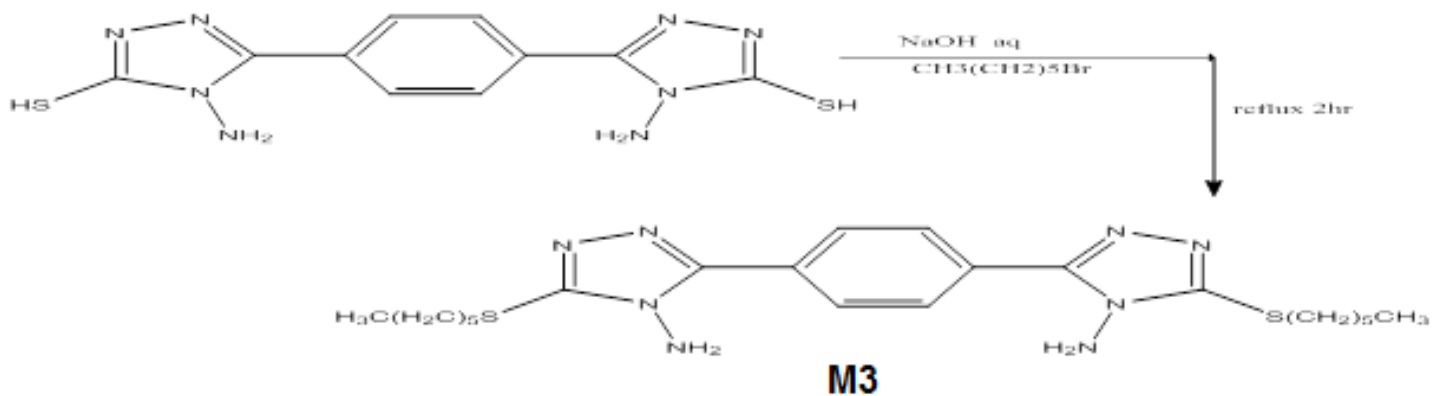

Polymer preparations:

Polymer I:

$1.43 \mathrm{~g}(0.005 \mathrm{~mole})$ of $\mathrm{M} 1$ was dissolved in $0.1 \mathrm{M} \mathrm{NaOH}$ solution. $0.42 \mathrm{ml}$ of dichloromethane was added drop wise and the reaction mixture was refluxed for of $4 \mathrm{hrs}$. The produced yellow polymer was filtered and dried under vacuum.<smiles>CC(C)(C)Cc1nnc(-c2ccc(-c3nnc(SC(C)(C)C)o3)cc2)o1</smiles>

\section{Polymer II:}

The same procedure for preparation polymer I was followed by polymerization of M1with $1.07 \mathrm{ml}$ of dibromobutane.

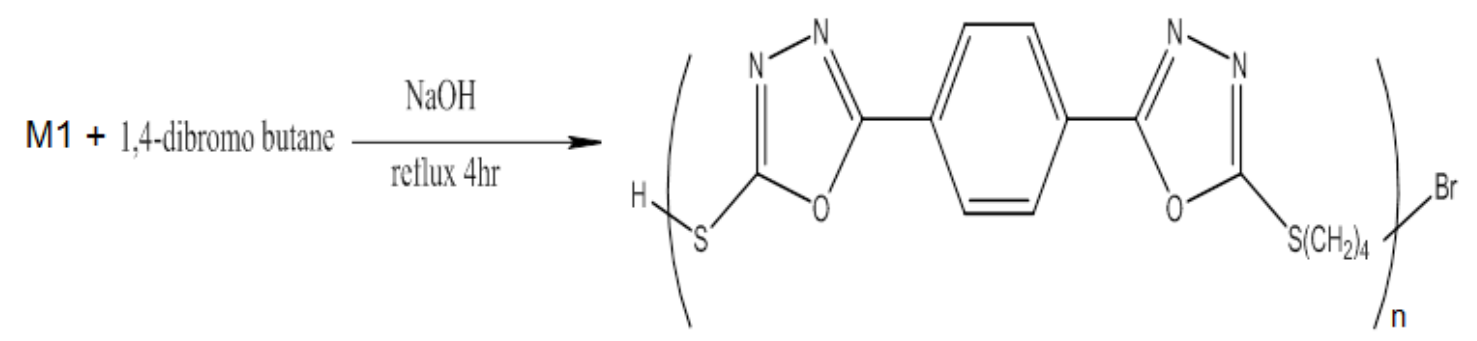

\section{and IV :}

Polymer III

These polymer are prepared by reaction of M2 monomer with 1,4-dibromo butane and dichloromethane respectively by following the same procedure of prepared polymers I and II.

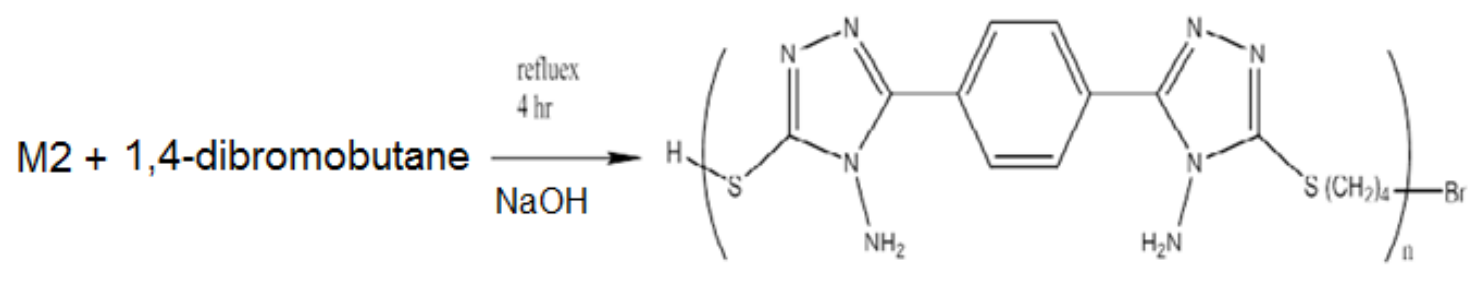

Pol.III 


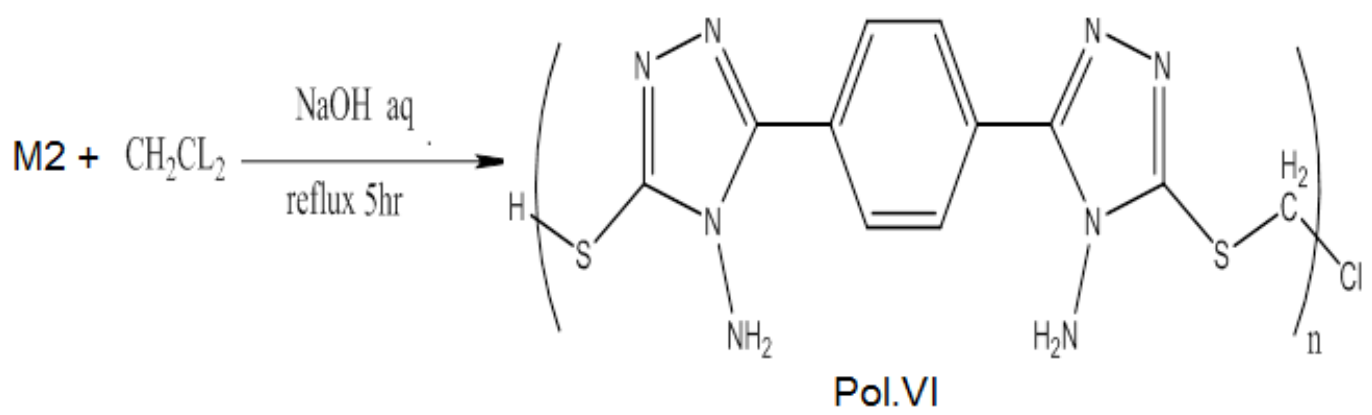

\section{Polymer V:}

$1 \mathrm{~g}(0.003 \mathrm{~mole})$ of M2 was mixed with $0.4 \mathrm{~g}(0.003 \mathrm{~mole})$ of terephthaldehyde in a test tube. The mixture was exposed to microwave radiation domestic microwave oven at $360 \mathrm{v}$ for 8 min the color of the mixture was changed to brown color.

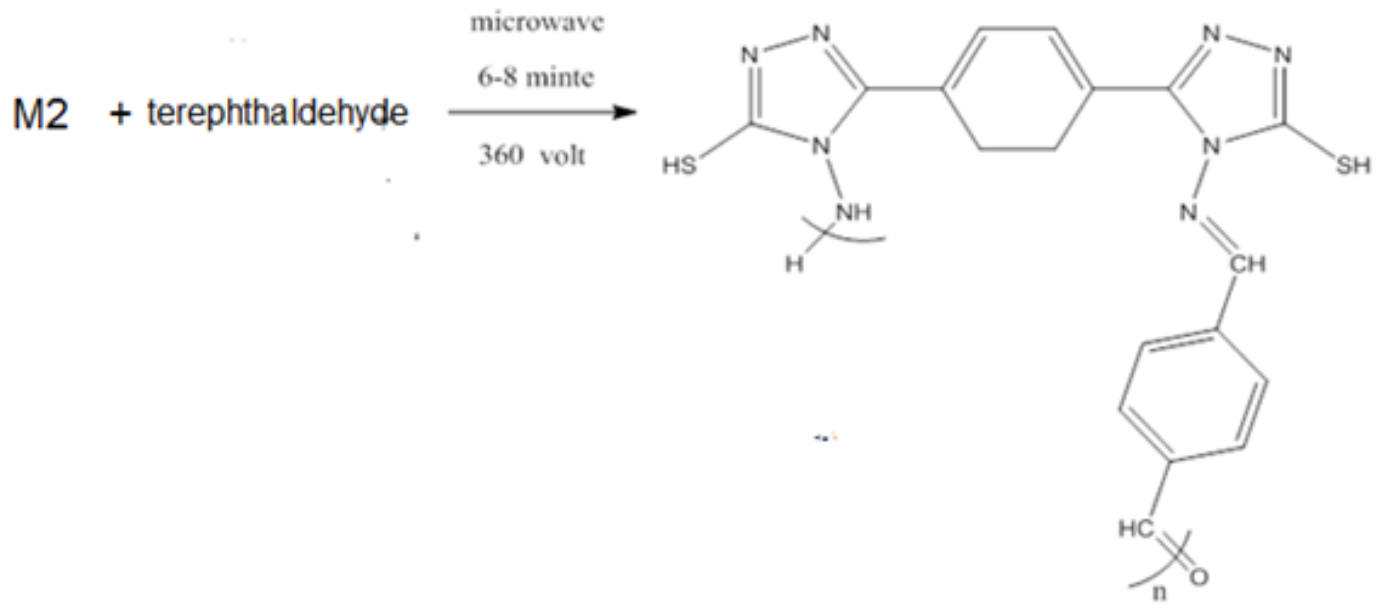

\section{Polymer VI:}

The same procedure was followed for preparation of polymer $\mathrm{V}$ by reaction of $1 \mathrm{~g}(0.005 \mathrm{~mole})$ of $\mathrm{M} 3$ with $0.4 \mathrm{~g}(0.005 \mathrm{~mole})$ of terephthaldehyde by using microwave radiation.

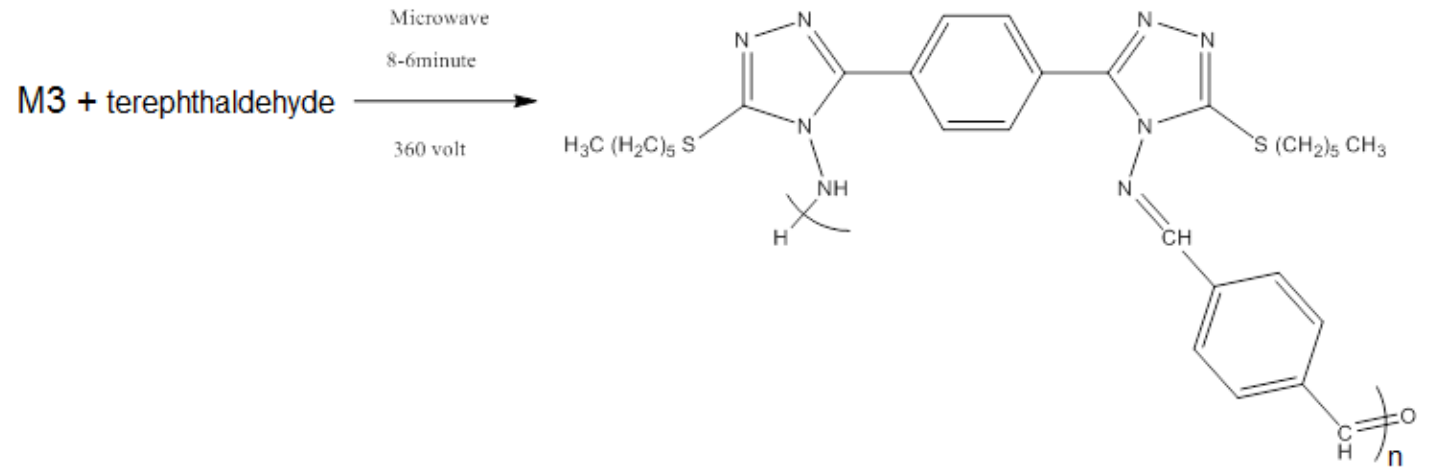




\section{Polymer VII:}

$1 \mathrm{ml}(0.005 \mathrm{~mole})$ of gluteraldehyde was mixed with $1.5 \mathrm{~g}(0.005 \mathrm{~mole})$ of M2 monomer in presence of $\mathrm{p}$ toluene sulfonic acid. The mixture was refluxed for $3 \mathrm{hrs}$. The product was filtered and washed with distilled water and dried under vacuum.
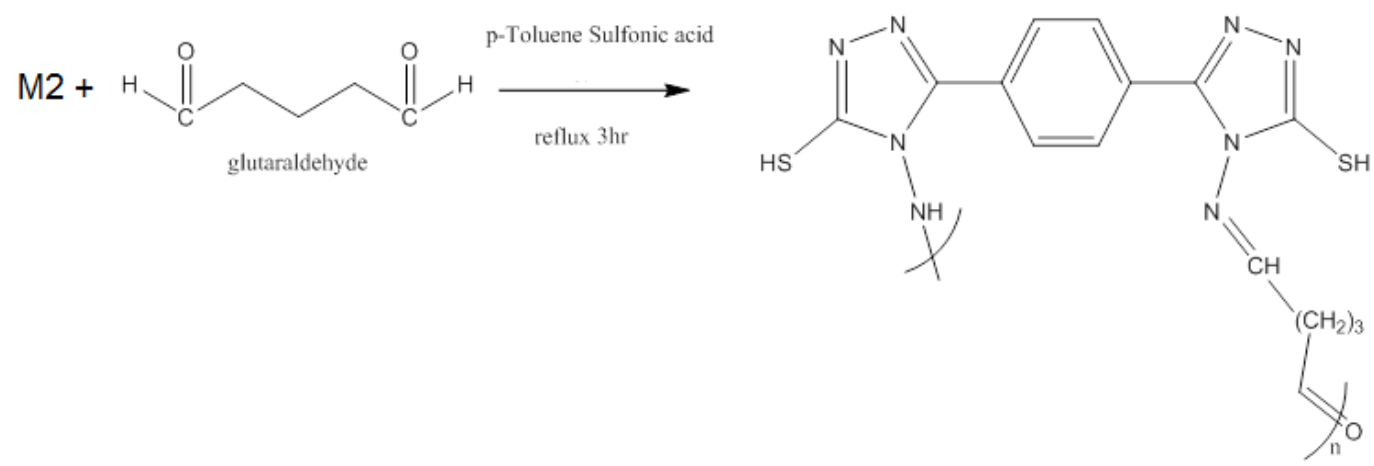

\section{Polymer VIII:}

Interfacial polymerization was used in this step. $(0.005$ mole $)$ of M2 monomer was dissolved in aqueous solution of sodium hydroxide in dry dioxane. $0.4 \mathrm{~g}(0.005 \mathrm{~mole})$ of terephthaldehyde was dissolved in dry dioxane. Adding the second solution to the first one slowly. The mixture was stirred until a yellow polymer was formed, filtered and dried under vacuum.

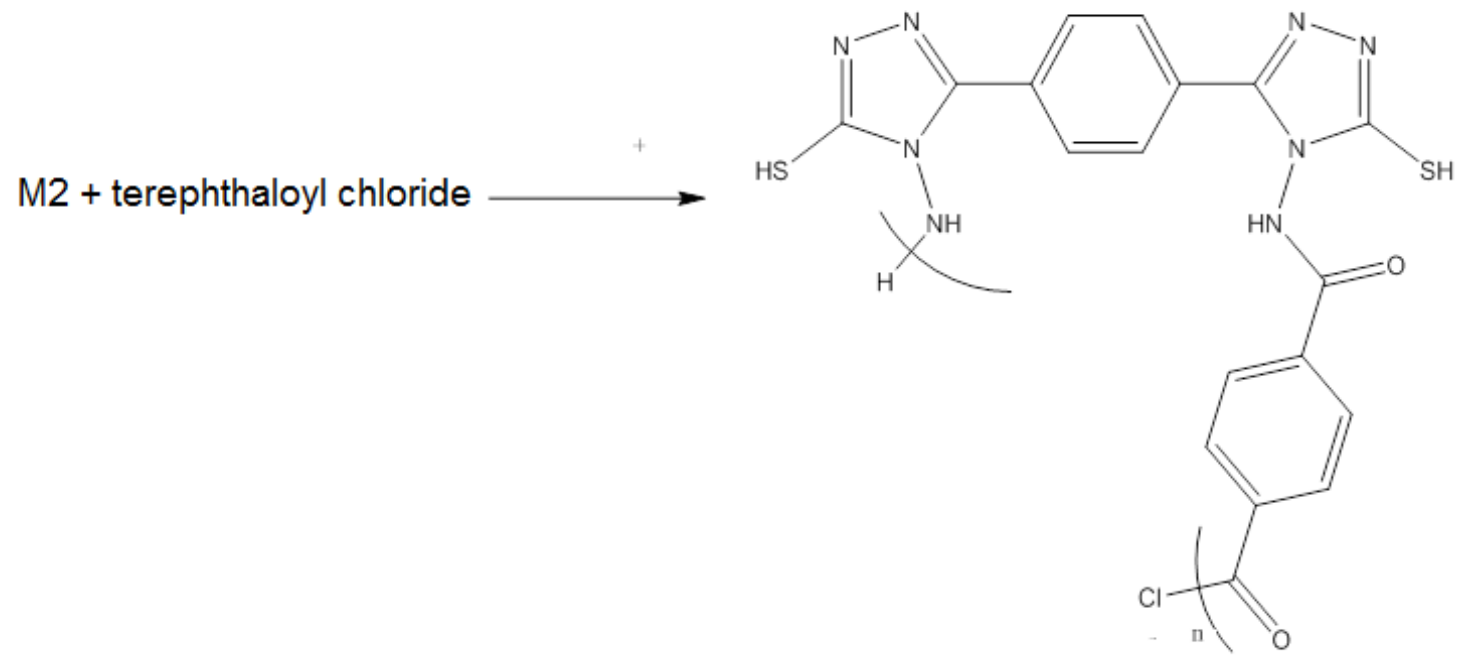

\section{Doping}

Two method was employed for doping :

\section{1-doping by mixing}

The pure polymers were mixed with iodine dopant with different ratios , and the mixture was pressed under 4 ton as a circular disc .

\section{2-vapor phase doping}

Known weight of circular dick of pure polymer was exposed to vapor of hydrochloric acid for different interval times. The difference between the weights of pure and doped polymers express the amount of dopant. 


\section{Electrical conductivity measurement}

Films of $2 \mathrm{~cm}$ diameter from the pure and doped polymers were performed. Volume electrical conductivity $(\sigma)$ was calculating by measuring the current flow in the volume of the specimen at different applied voltage according to the equation: (14)

$\sigma=\mathrm{Id} / \mathrm{AE}$

Where: $\sigma=$ volume conductivity $\left(\mathrm{S} . \mathrm{Cm}^{-1}\right)$

$\mathrm{I}=$ the flow current (ampere)

$\mathrm{d}=$ thickness of the specimen $(\mathrm{Cm})$

$\mathrm{A}=$ active surface area of the specimen $\left(\mathrm{cm}^{2}\right)$

$\mathrm{E}=$ applied voltage (volt)

\section{Synthesis and characterization:}

\section{Result and Discussions}

The prepared monomers are outlined in table(1)

Table (1):Chemical structure of the prepared monomers

monomers

The FTIR spectrum of the monomers (figures 1,2 and3) show clear bands due to $\mathrm{C}=\mathrm{N}$, C-O-C, C-S, S-H and aromatic finger print absorption bands (table2)

Table (2): FTIR band frequencies of the monomers

\begin{tabular}{|c|c|c|c|c|}
\hline \multirow{2}{*}{ monomers } & \multicolumn{4}{|c|}{ IR v $\left(\mathbf{c m}^{-1}\right) \mathbf{K B r}$} \\
\cline { 2 - 5 } & $\mathbf{C}=\mathbf{N}$ & S-H & C-S & $\begin{array}{c}\text { C-O-C } \\
\text { V-Cy } \\
\text { Vas }\end{array}$ \\
\hline M1 & 1666 & 2625 & 715 & 1066 \\
\hline M2 & 1616 & 2590 & 767 & \\
\hline M3 & 1606 & - & 698 & \\
\hline
\end{tabular}

The polymerization reaction of the monomers were performed by using polycondensation technique.(table 3).

Polymer I and II were prepared through the reaction of M1with methylene chloride and 1,4-dibromo butane respectively. The FTIR spectra (table 4) of the polymers (figures 4 and 5) show appearance of new bands in comparison with the spectra of the monomers at $2924 \mathrm{~cm}^{-1}$ and $2929 \mathrm{~cm}^{-1}$ which are 
related to $v(\mathrm{C}-\mathrm{H})$ aliphatic. While the band appeared at $715 \mathrm{~cm}^{-1}$ in monomers spectrum was disappeared in polymers spectra.

Polymer III and IV were prepared by polycondensation of monomer M2 with 1,4-dibromo butane and methylene chloride respectively. The FTIR spectra of the polymers (figures 6 and7) show the appearance of new bands in comparison with the spectrum of the monomer at $2931 \mathrm{~cm}^{-1}$ and $2839 \mathrm{~cm}^{-1}$ which are attributed to $v(\mathrm{C}-\mathrm{H})$ aliphatic in polymers III and IV respectively.

The azomethine moiety was created within the backbone of polymer $\mathrm{V}$ via the polymerization of monomer M2 with terephthaldehyde. The FTIR spectrum of the polymer shows absorption bands in 1454-1469 cm-1duo to azomethine group. Long aliphatic chain was introduced to M2 through the S-H group to produce M3 monomer. For synthesis polymer VI, M3 monomer was polymerized with terephthaldehyde. In comparison with polymer V, the FTIR spectra of the polymer VI show appearance of absorption bands related to $v(\mathrm{C}-\mathrm{H})$ aliphatic at $2835 \mathrm{~cm}-1$ In the other hand polymer VII was produce by polymerization of monomer M3 with glutaraldehyde. The FTIR spectrum of the polymer VII show the presence of $\mathrm{C}=\mathrm{N}$ absorption band at $1469 \mathrm{~cm}-1$. Polymer VIII was synthesized through polymerization of M2 with terephthaloyl dichloride. The peak at $1639 \mathrm{~cm}-1$ appeared in FTIR is related to $v(\mathrm{C}=\mathrm{O})$ amide.

table 3:Chemical formula of the prepared polymers

\begin{tabular}{|c|c|c|c|}
\hline polymers & Monomer 1 & Monomer 2 & Chemical formula \\
\hline I & M1 & $\mathrm{CH}_{2} \mathrm{Cl}_{2}$ & \\
\hline II & M1 & 1,4-dibromo butane & \\
\hline III & M2 & 1,4-dibromo butane & \\
\hline IV & M2 & $\mathrm{CH}_{2} \mathrm{Cl}_{2}$ & \\
\hline V & M2 & Terephthaldehyde & \\
\hline VI & M3 & Terephthaldehyde & \\
\hline
\end{tabular}




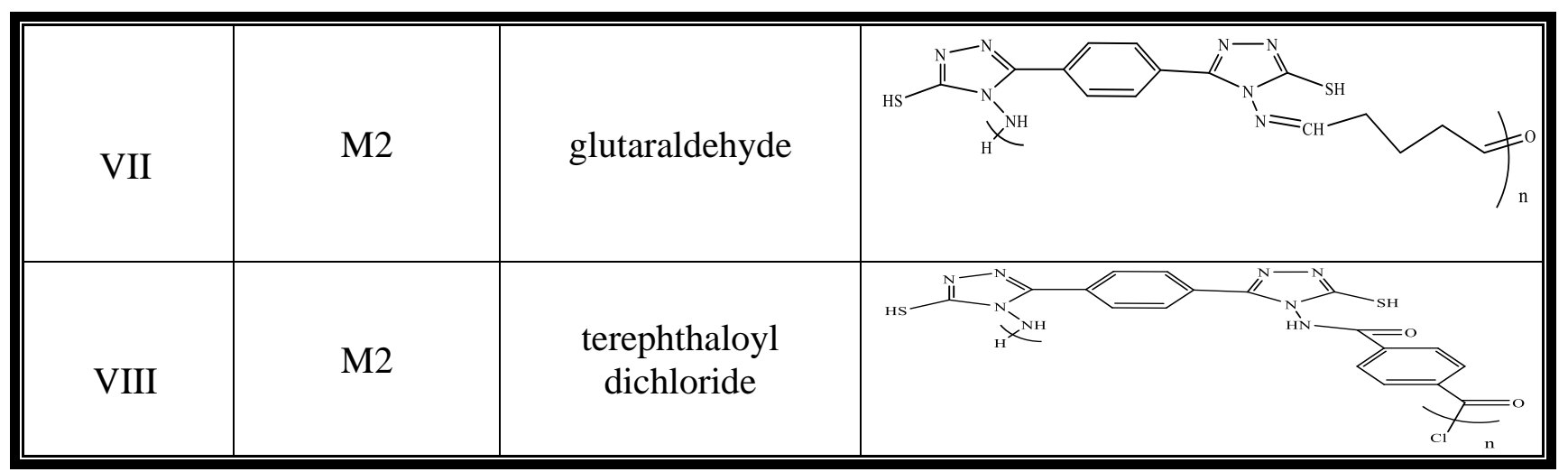

Table 4: FTIR band frequencies of the prepared polymers.

\begin{tabular}{|c|c|c|c|c|c|c|c|c||}
\hline \multirow{2}{*}{ Polymer no. } & \multicolumn{7}{|c||}{ IR v(cm-1) KBr } \\
\cline { 2 - 10 } & C=N & $\begin{array}{c}\text { C-O-C } \\
\text { V.c } \\
\text { Vas }\end{array}$ & $\mathbf{N H}_{2}$ & C-S & S-H & $\begin{array}{c}\text { C-H } \\
\text { Aromatic }\end{array}$ & C-H & Other \\
\hline \hline Pol. I & 1599 & $\begin{array}{c}1037 \\
1381\end{array}$ & - & 713 & - & $\begin{array}{c}1114,1182 \\
1273,1375\end{array}$ & 2929 & \\
\hline Pol.II & 1658 & $\begin{array}{c}1039 \\
1375\end{array}$ & - & 729 & & $\begin{array}{c}1114,1186 \\
1273,1381\end{array}$ & 2928 & \\
\hline Pol. III & 1599 & - & 3200 & 715 & - & $\begin{array}{c}1111,1130 \\
1209,1284\end{array}$ & 2931 & \\
\hline Pol. IV & 1566 & - & 3327 & 715 & - & $\begin{array}{c}1114,1143 \\
1269,1296\end{array}$ & 2941 & \\
\hline pol.V & 1614 & - & - & 713 & 2350 & $\begin{array}{c}1150,1209 \\
1273,1309\end{array}$ & - & 1464 for C=N \\
\hline pol.VI & 1599 & - & - & & & $\begin{array}{c}1112,1209 \\
1273,1404\end{array}$ & 2950 & 1454 for C=N \\
\hline Pol. VII & 1647 & - & - & & 2408 & $\begin{array}{c}1066,1118 \\
1170,1274\end{array}$ & 2937 & 1469 for C=N \\
\hline pol.VIII & 1562 & - & 3331 & 721 & 2408 & $\begin{array}{c}1114,1149 \\
1267,1296\end{array}$ & & $\begin{array}{c}\text { For C=O amide } \\
1639\end{array}$ \\
\hline
\end{tabular}

The chemical structure of prepared polymers were confirmed through the $\mathrm{CHN}$ elemental analysis (table $5)$. 
Table(5): CHN elemental analysis of the prepared polymes

\begin{tabular}{|c|c|c|c|c|c|c||}
\hline \multirow{2}{*}{ Poly No. } & \multicolumn{2}{|c|}{ \% C } & \multicolumn{2}{c|}{ \%H } & \multicolumn{2}{c|}{$\% \mathbf{N}$} \\
\hline \multirow{2}{*}{ I } & Calc. & found & Calc. & found & Calc. & found \\
\cline { 2 - 7 } & 43.3 & 42.5 & 2.05 & 2.59 & 20.0 & 19.4 \\
\hline II & 50.6 & 50 & 3.6 & 3.2 & 16.8 & 16 \\
\hline III & 39.4 & 40.7 & 3.4 & 3.9 & 36.4 & 35.0 \\
\hline IV & 46.4 & 45.06 & 4.4 & 5.0 & 31.0 & 30.9 \\
\hline V & 53.3 & 54.86 & 3.2 & 3.55 & 27.6 & 27.2 \\
\hline VI & 62.3 & 63.56 & 6.0 & 5.7 & 20.5 & 20 \\
\hline VII & 48.6 & 50.8 & 4.0 & 4.1 & 30.1 & 28.0 \\
\hline VIII & 49.5 & 50.5 & 2.7 & 3.07 & 25.6 & 25.23 \\
\hline
\end{tabular}

\section{Electrical conductivity :}

Table (6) shows the electrical conductivity of the pureed prepared polymers at room temperature .

Table(6):Electrical conductivity $(\sigma)$ of the prepared polymers

\begin{tabular}{|c|c|}
\hline polymer & $\sigma \mathrm{S} . \mathrm{Cm}^{-1}$ \\
\hline I & $3.8 \times 10^{-8}$ \\
\hline II & $5.74 \times 10^{-8}$ \\
\hline III & $4.4 \times 10^{-8}$ \\
\hline VI & $5.9 \times 10^{-10}$ \\
\hline V & $4.1 \times 10^{-10}$ \\
\hline IV & $12.25 \times 10^{-12}$ \\
\hline IIV & $5.4 \times 10^{-10}$ \\
\hline IIIV & $8.3 \times 10^{-9}$ \\
\hline
\end{tabular}

The results indicate that the major factor effect on conductivity is the chemical structure of the polymer. It was noticed that the electrical conductivity of polymer III is higher than that of polymer I, where by the backbone of polymer II have higher long aliphatic (butane) moiety than that in polymer I (methane) .The butane chain in polymer II gives flexibility to the polymer chain and increase the conductivity (15). In comparison between polymer I and polymer IV polymer I have higher conductivity than that of polymer IV. This can be explained by that the lone pair of electrons on oxygen atom in polymer I have ability in sharing the conjugation more than the lone pair of electrons in nitrogen atom in polymer I. This affect can also be noticed in comparison between the conductivity of polymer II with III. The advantage of presence of long aliphatic side group in the polymer chain (polymer VI) is to increase the solubility, but the disadvantage is reducing the electrical conductivity. This factor can be clearly noticed in comparison the conductivity of polymer $\mathrm{V}$ with polymer VI . 
The type of bonding group can also effect on the electrical conductivity. This factor can be noticed in comparison between polymer VIII( with amide group) and polymer V with azomethine group. The polymer VIII have higher conductivity than polymer V.

\section{Doping effect :}

It was well known that the electrical conductivity of polymer is practically related to the transfer of the charge carriers along the conjugated chain. The transfer of the charge carriers is through sites created by the effecting of dopant molecules (ref). The polymer can have some center of electron donor or acceptor through which the dopant can associate to create the charge carriers.

The studied polymers are doped with different ratios of iodine. It was noticed that the electrical conductivity was increased to some extent. Table 7 shows the effect of doping by iodine on the electrical conductivity of polymers .Generally oxygen and nitrogen atoms within the backbone of the polymer chain can be considered as a sits for doping acting.

Table (7): electrical conductivity of polymers doping with different ratio of iodine

\begin{tabular}{|c|c|c|c|c|c|c|c||}
\hline $\begin{array}{c}\text { Polyme } \\
\text { r no. }\end{array}$ & $\boldsymbol{\sigma} \mathbf{~ s . c m}^{-1}$ & $\begin{array}{c}\text { ratio of } \\
\text { doping }\end{array}$ & $\boldsymbol{\sigma} \mathbf{s . c m}-\mathbf{1}$ & $\begin{array}{c}\text { ratio of } \\
\text { doping }\end{array}$ & $\boldsymbol{\sigma} \mathbf{s . c m}^{-1}$ & $\begin{array}{c}\text { ratio of } \\
\text { doping }\end{array}$ & $\boldsymbol{\sigma}$ s.cm$^{-1}$ \\
\hline \hline I & $3.8 \mathrm{E}-8$ & 0.023 & $2 \mathrm{E}-7$ & 0.039 & $3.4 \mathrm{E}-7$ & 0.062 & $3.6 \mathrm{E}-7$ \\
\hline II & $5.74 \mathrm{E}-8$ & 0.024 & $4.5 \mathrm{E}-7$ & 0.044 & $5.4 \mathrm{E}-7$ & & \\
\hline III & $4.4 \mathrm{E}-8$ & 0.018 & $5.2 \mathrm{E}-8$ & 0.036 & $1.1 \mathrm{E}-7$ & 0.061 & $9.8 \mathrm{E}-7$ \\
\hline IV & $5.9 \mathrm{E}-10$ & 0.031 & $9.2 \mathrm{E}-10$ & 0.053 & $1.7 \mathrm{E}-9$ & 0.065 & $8.5 \mathrm{E}-9$ \\
\hline V & $4.1 \mathrm{E}-10$ & 0.022 & $8.1 \mathrm{E}-10$ & 0.041 & $12.3 \mathrm{E}-10$ & & \\
\hline VI & $12 \mathrm{E}-12$ & 0.021 & $2.8 \mathrm{E}-11$ & 0.034 & $7.8 \mathrm{E}-11$ & 0.055 & $13.3 \mathrm{E}-10$ \\
\hline VII & $5.4 \mathrm{E}-10$ & 0.013 & $9.1 \mathrm{E}-11$ & 0.034 & $1.96 \mathrm{E}-9$ & 0.05 & $3.2 \mathrm{E}-9$ \\
\hline VIII & $8.3 \mathrm{E}-9$ & 0.031 & $6.6 \mathrm{E}-9$ & 0.048 & $9.5 \mathrm{E}-9$ & & \\
\hline
\end{tabular}

The results indicate that polymer with nitrogen atom (polymers V,VI,VII) have higher responding to doping with iodine more than polymers with oxygen atom.

Table (8) shows the effect of doping by acid on the electrical conductivity of polymers.

The acid can protonate the heterogeneous atoms $(\mathrm{N}, \mathrm{S}, \mathrm{O})$ in organic compounds. The sites of protonation is responsible for creating the charge carriers. The results show that the efficiency of doping by acid is depend on the type of polymer. The increasing of the electrical conductivity of polymers with oxadiazole ring (polymers I and II) is very low in comparison with polymers of triazole rings .This can be explained by that the efficiency of protonation of nitrogen atom is higher than that of oxygen atoms. 
Table (8): electrical conductivity of polymers doping with different ratio of acid

\begin{tabular}{|c|c|c|c|c|c|c|c||}
\hline $\begin{array}{c}\text { Polymer } \\
\text { no. }\end{array}$ & $\boldsymbol{\sigma}$ s.cm$^{-1}$ & $\begin{array}{c}\text { ratio of } \\
\text { doping }\end{array}$ & $\begin{array}{c}\text { Conductivity } \\
\mathbf{s . c m}\end{array}$ & $\begin{array}{c}\text { ratio } \\
\text { of } \\
\text { dopin } \\
\text { g }\end{array}$ & $\boldsymbol{\sigma}$ s.cm-1 $^{-1}$ & $\begin{array}{c}\text { ratio of } \\
\text { doping }\end{array}$ & $\boldsymbol{\sigma}$ s.cm $^{-1}$ \\
\hline \hline I & $3.8 \mathrm{E}-8$ & 0.023 & $2 \mathrm{E}-7$ & 0.039 & $3.4 \mathrm{E}-7$ & 0.062 & $3.6 \mathrm{E}-7$ \\
\hline II & $5.74 \mathrm{E}-8$ & 0.024 & $4.5 \mathrm{E}-7$ & 0.044 & $5.4 \mathrm{E}-7$ & & \\
\hline III & $4.4 \mathrm{E}-8$ & 0.018 & $5.2 \mathrm{E}-8$ & 0.036 & $1.1 \mathrm{E}-7$ & 0.061 & $9.8 \mathrm{E}-7$ \\
\hline IV & $5.9 \mathrm{E}-10$ & 0.031 & $9.2 \mathrm{E}-10$ & 0.053 & $1.7 \mathrm{E}-9$ & 0.065 & $8.5 \mathrm{E}-9$ \\
\hline V & $4.1 \mathrm{E}-10$ & 0.022 & $8.1 \mathrm{E}-10$ & 0.041 & $12.3 \mathrm{E}-10$ & & \\
\hline VI & $12 \mathrm{E}-12$ & 0.021 & $2.8 \mathrm{E}-11$ & 0.034 & $7.8 \mathrm{E}-11$ & 0.055 & $13.3 \mathrm{E}-10$ \\
\hline VII & $5.4 \mathrm{E}-10$ & 0.013 & $9.1 \mathrm{E}-11$ & 0.034 & $1.96 \mathrm{E}-9$ & 0.05 & $3.2 \mathrm{E}-9$ \\
\hline VIII & $8.3 \mathrm{E}-9$ & 0.031 & $6.6 \mathrm{E}-9$ & 0.048 & $9.5 \mathrm{E}-9$ & & \\
\hline
\end{tabular}

\section{Conclusion}

The electrical conductivity of the conjugation polymers can be affected by different factors. The presence of long aliphatic segment within the back bone of the polymer chain can increased the electrical conductivity of the polymer by increasing the flexibility. On the other hand the presence of aliphatic segment interrupt the conjugation and decrease the electrical conductivity. The presence of the hetero atoms in the main chain of the polymer will enhanced the electrical conductivity by the participation of the lone pair of electron of the hetero atoms in the conjugation system. Also te hetero atoms can be considered as a site to host the dopant molecule and create the charge carriers.

\section{Refrences}

1- Shirakawa, , H. Louis E. J. MacDiarmid, A.G. C.K. Chiang and Heeger, A.J. Chem, J.C.S., Comm. Physical Rev. 578, (1977).

2- Heeger, A.J.; Kirelson, S.; Schrieffr, J.R.,and Su, W.P.. Solitons in Conducting

Polymers.Rev. Mod. Phys.,60,781p.( 1988)

3- Mishra, A.K., Journal of atomic, condensate \&nano physics, 5, No.2, pp 159-193 (2018).

4- Barford. W, International Series of Monographs on Physics, 129. Electronic and Optical Properties of Conjugated Polymers, Oxford University Press Inc., New York, 2005, p1.

5- Carraher, C.E.., Dekkerr, M., Semoury/ Carraher's polymer chemistry, $4^{\text {th }}$ edition, New York (1996). 6- Khattab,A.F. and Abbas,M.F., International Journal of Enhanced Research in Science, Technology \& Engineering, 4(8),PP 1-10. (2015).

7- Khattab A. F. and AL-Chalabi R. M.A., Tikrit Journal of Pure Science 18 (3) 
(2013)

8- Chen H. and Cao Y., Acc. Chem. Res., 42.1709 (2009).

9- Ayoob, H. A., Khattab,A.F. and Al Taan, L. M., Journal of Education and Science, 29, No.4, pp 140153 (2020).

10- Al Assawi, A. M., and Yaseen, H. K., Journal of Chemical and Pharmaceutical Research,8(8), 241247 (2016).

11- Yang Wang and Tsuyoshi Michinobu, Journal of Materials Chemistry C,4,6200 (2016).

12-Majeed, A.H. and Al- Tikrity, E.T.B, Polymer and Polymer Composites, pp1-12,(2020).

13- Ayoob, H.A., Al Taan, L. and Khattab,A.F., Rafidain J. of science,29(4), pp66-76 (2020).

14- ASTM, Annual Book of standards, D.C. Resistance or conductivity of insulating materials D527, part 39. Philadelphia :American society of testing and materials, 1981.

15- Khattab, A. F. , Raffidin journal of science, 19 No2, pp8-15 (2008).

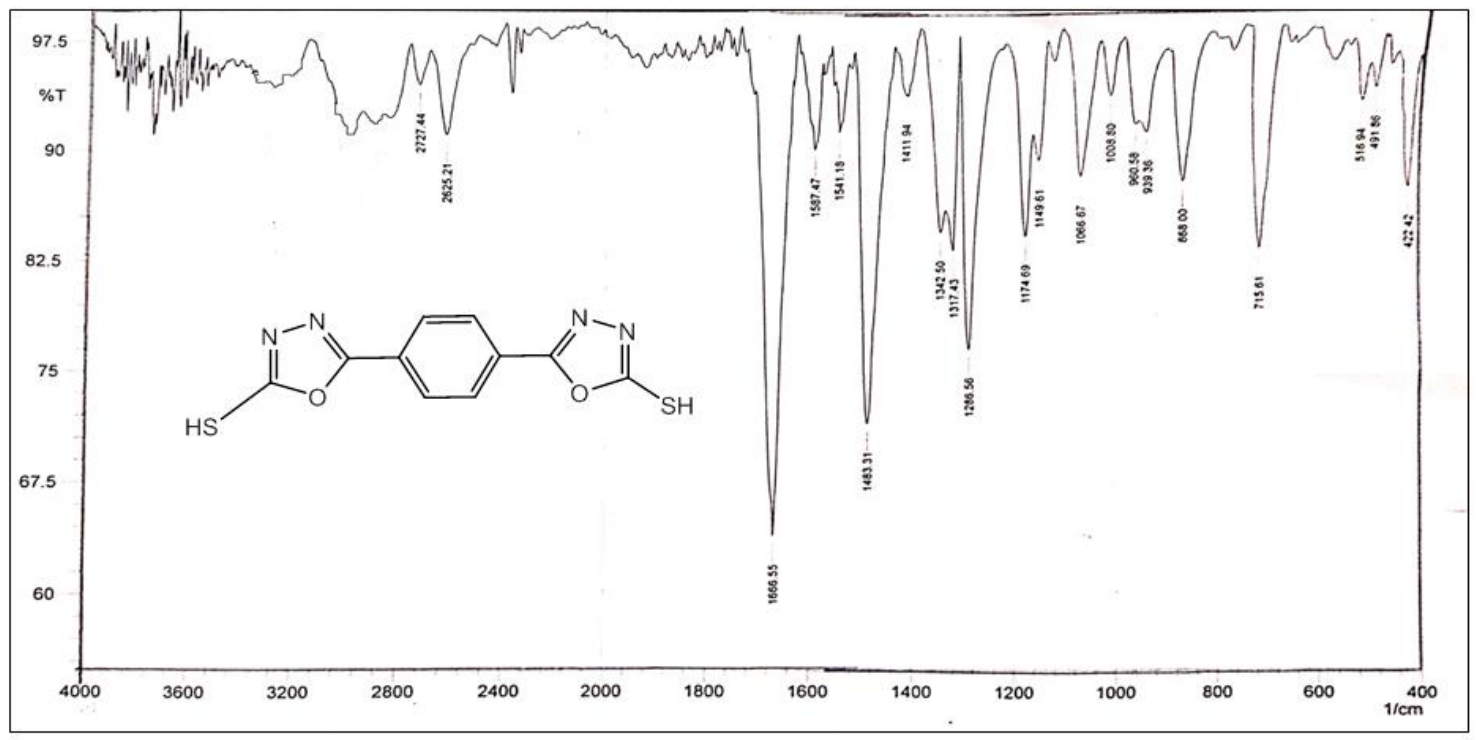

Figure(1): IR spectrum of monomer M1

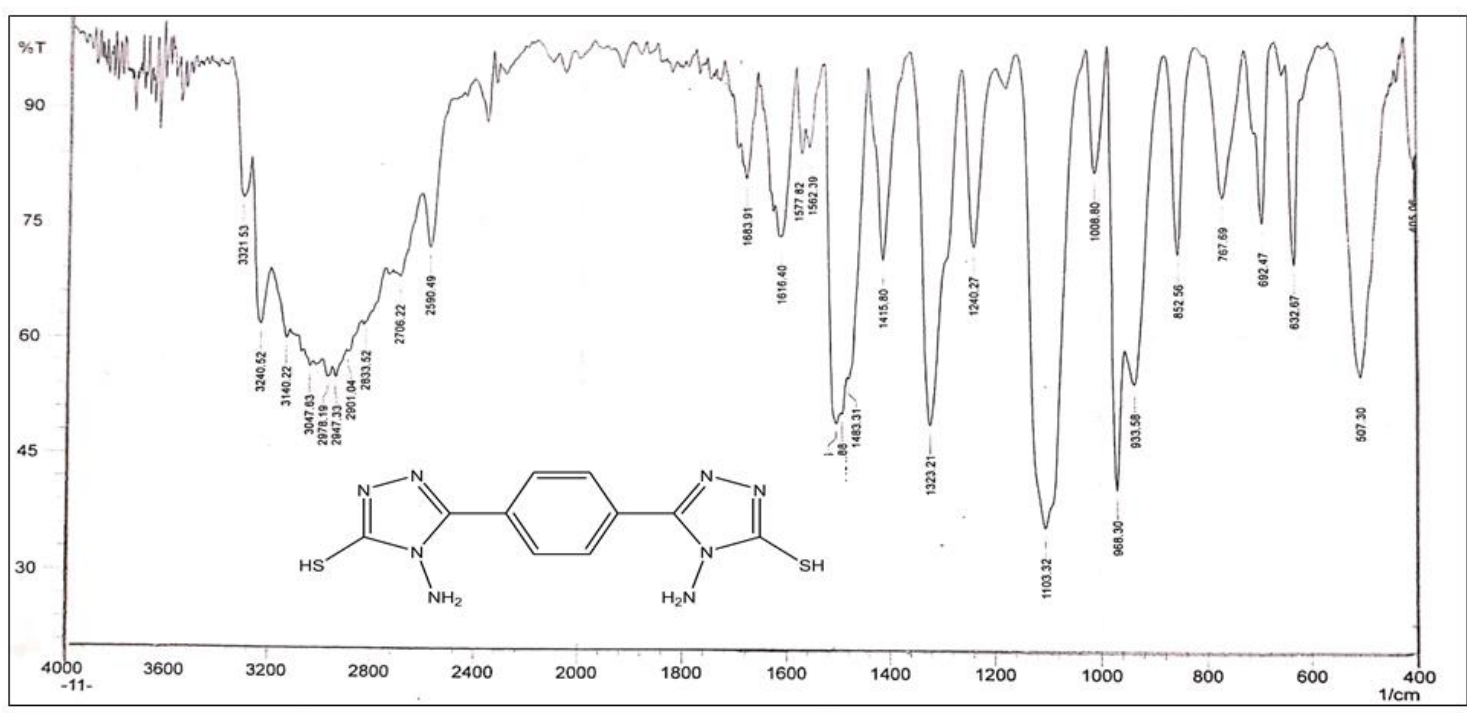

Figure(2): IR spectrum of monomer M2 
Journal of Education and Science (ISSN 1812-125X), Vol: 30, No: 2, 2021 (104-120)

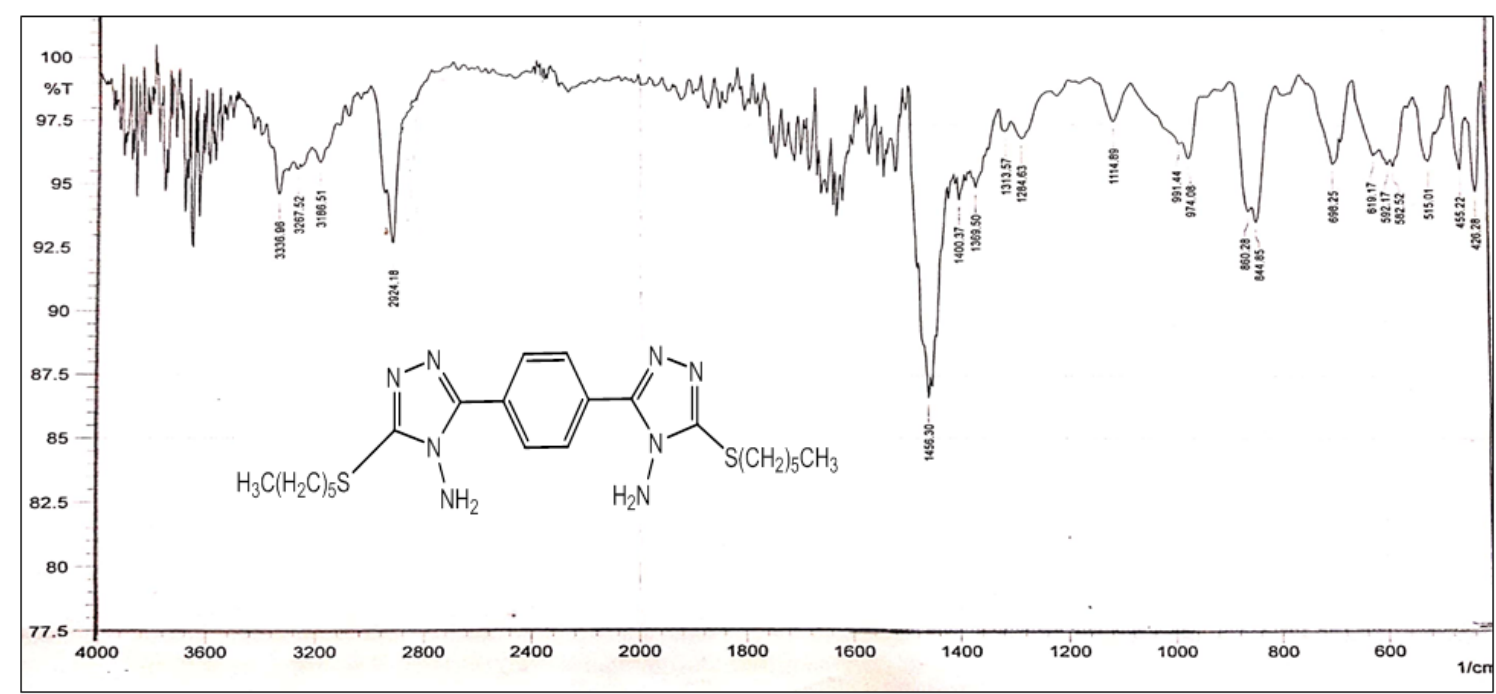

Figuer(3): IR spectrum of monomer M3

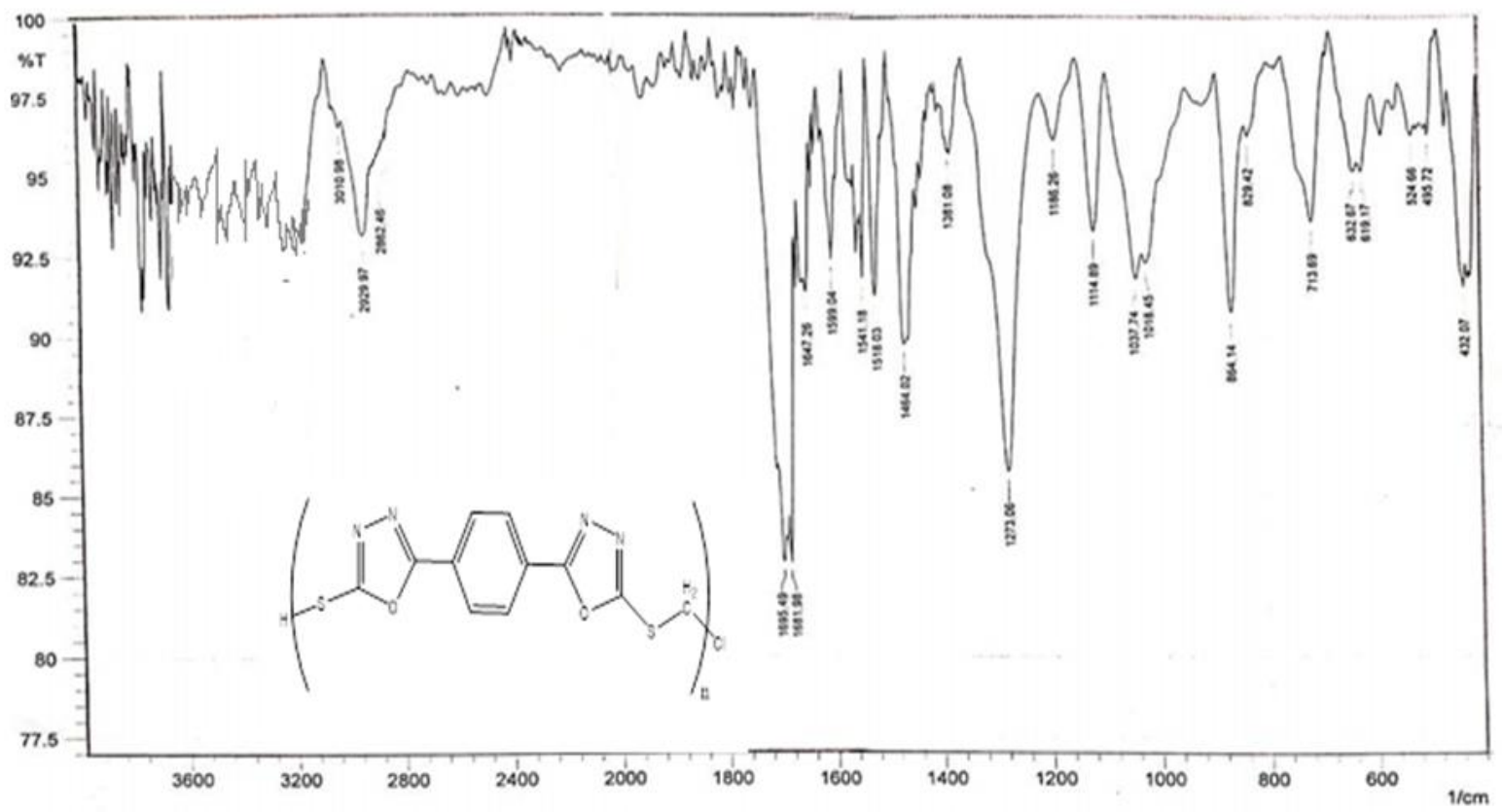

Figure (4): IR spectrum of polymer P1 


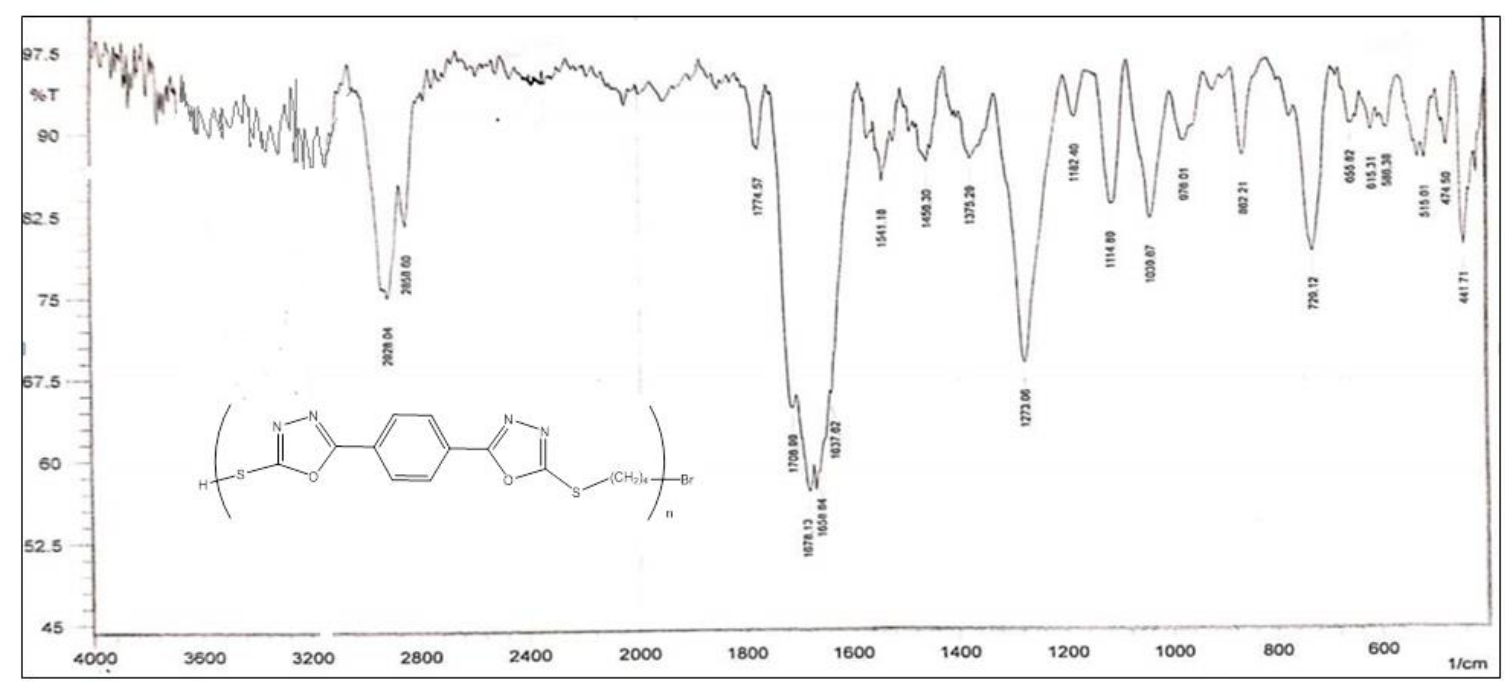

Figure (5): IR spectrum of polymer PII
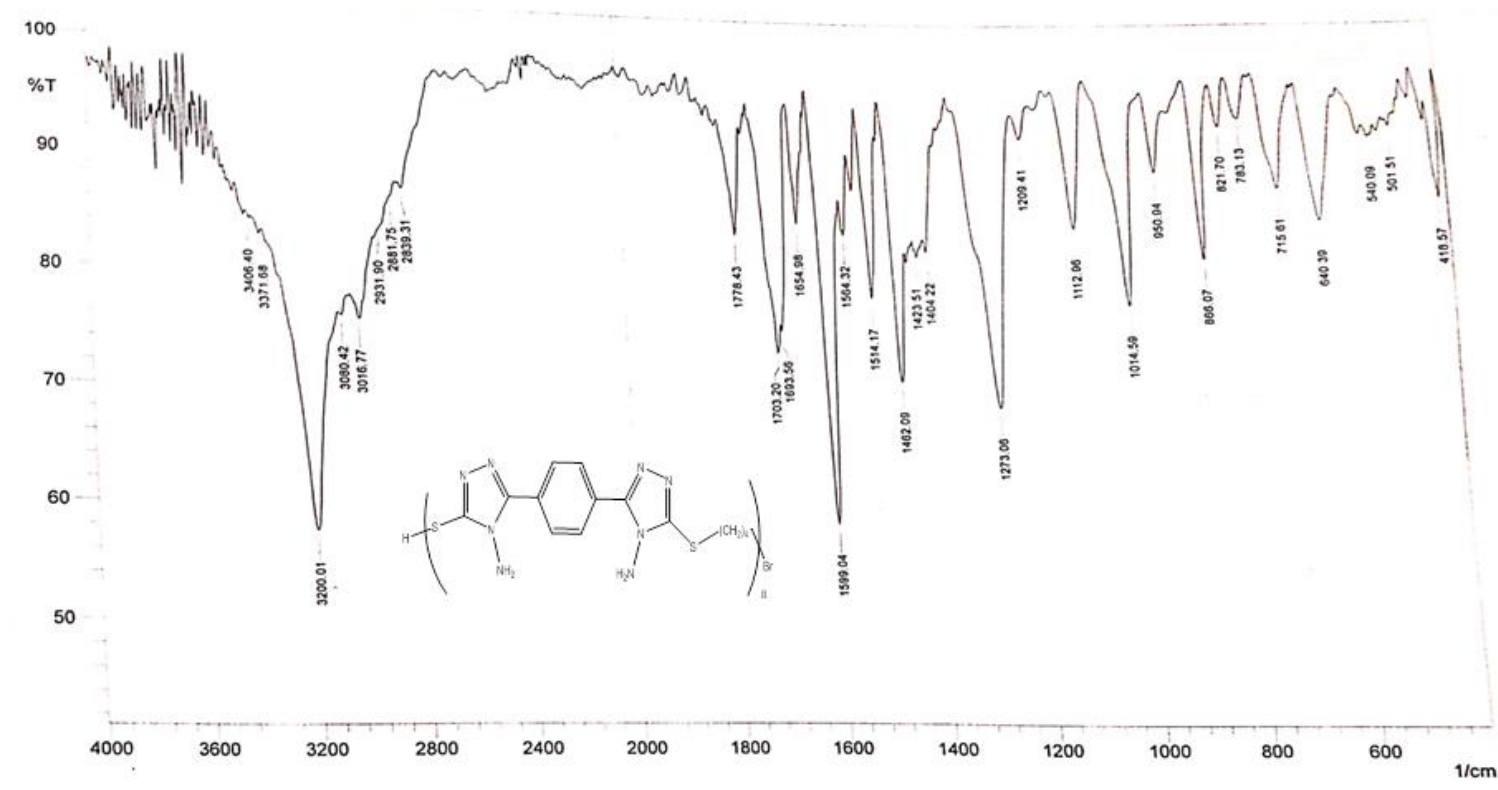

Figure (6): IR spectrum of polymer PIII 


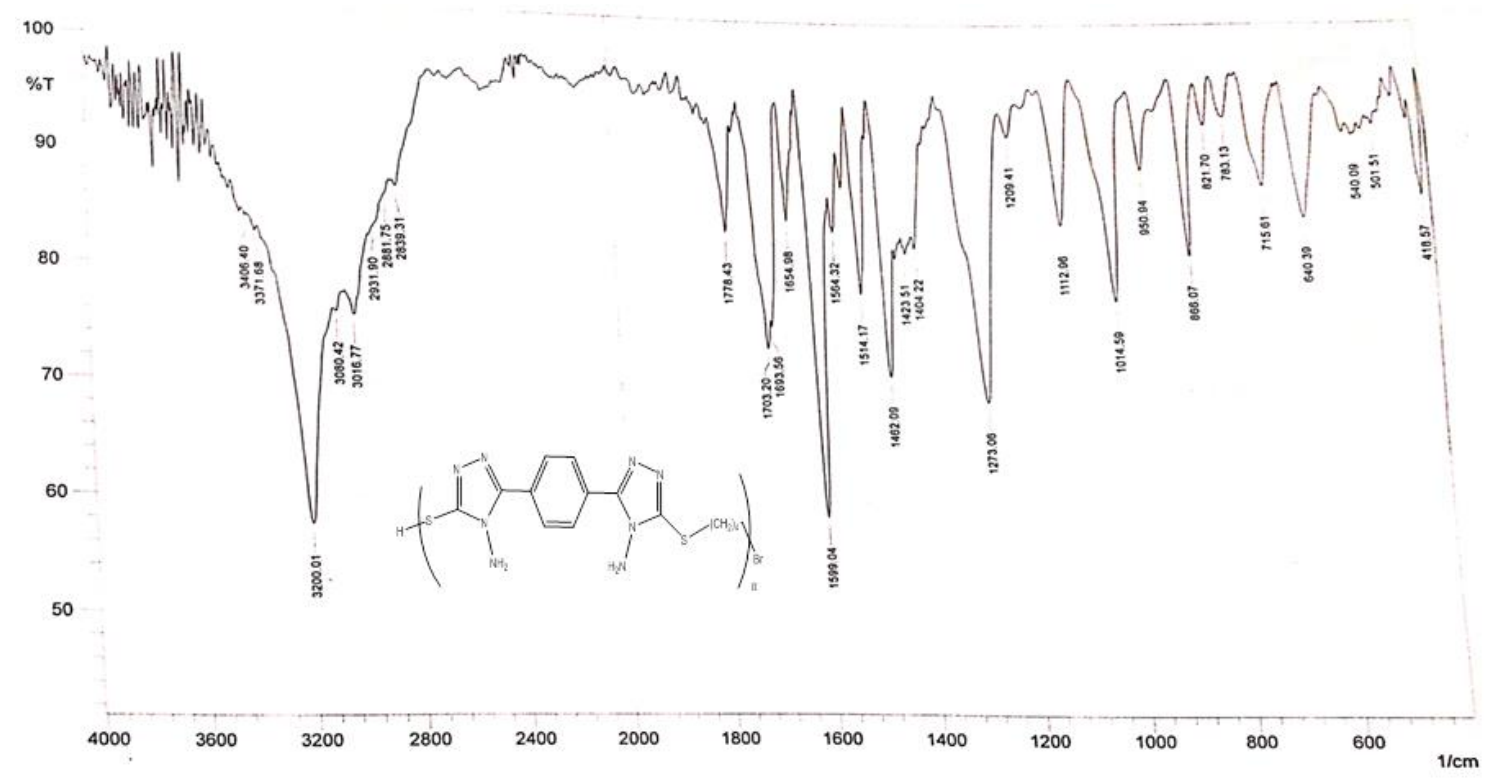

Figure (7): IR spectrum of polymer PIV

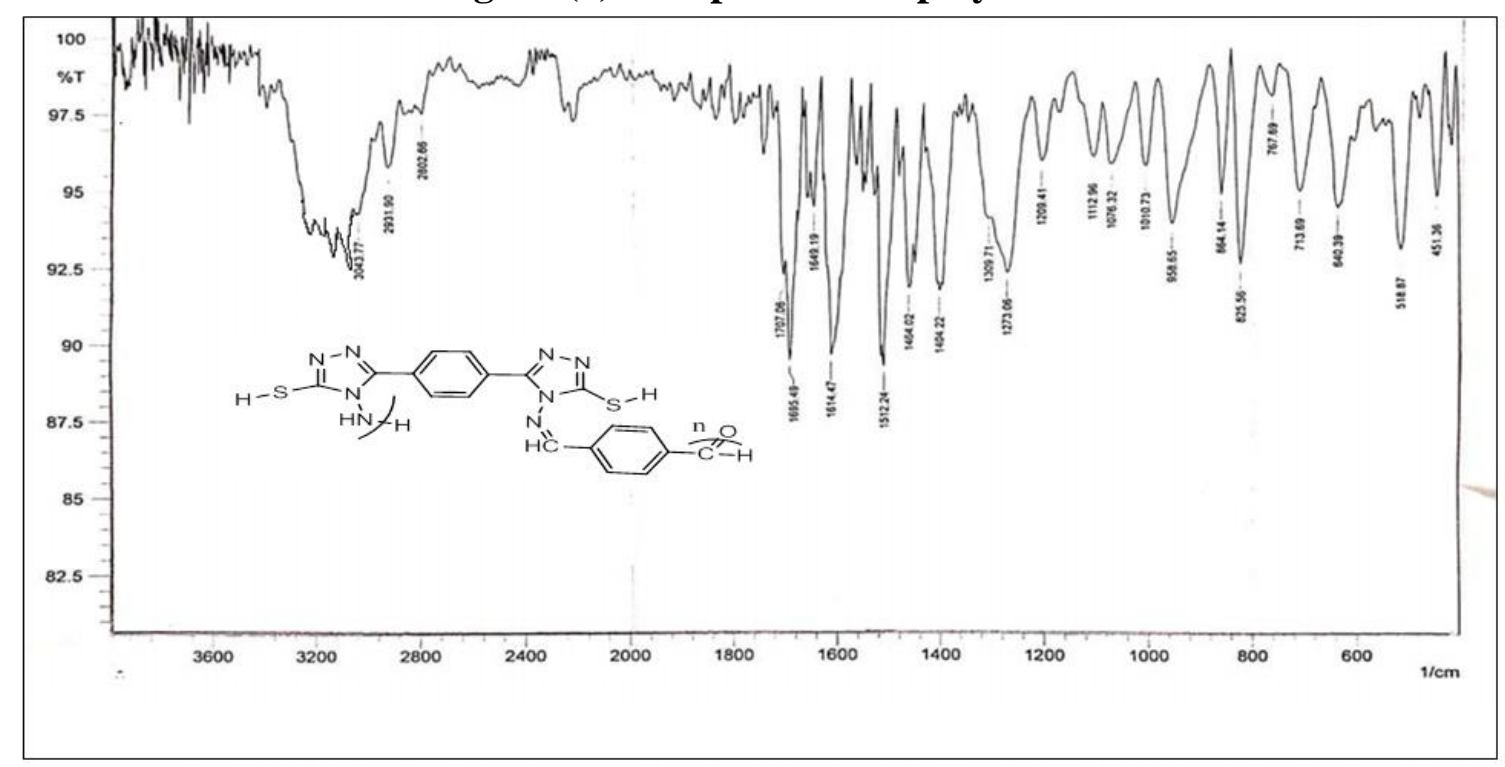

Figure (8): IR spectrum of polymer PV 
Journal of Education and Science (ISSN 1812-125X), Vol: 30, No: 2, 2021 (104-120)

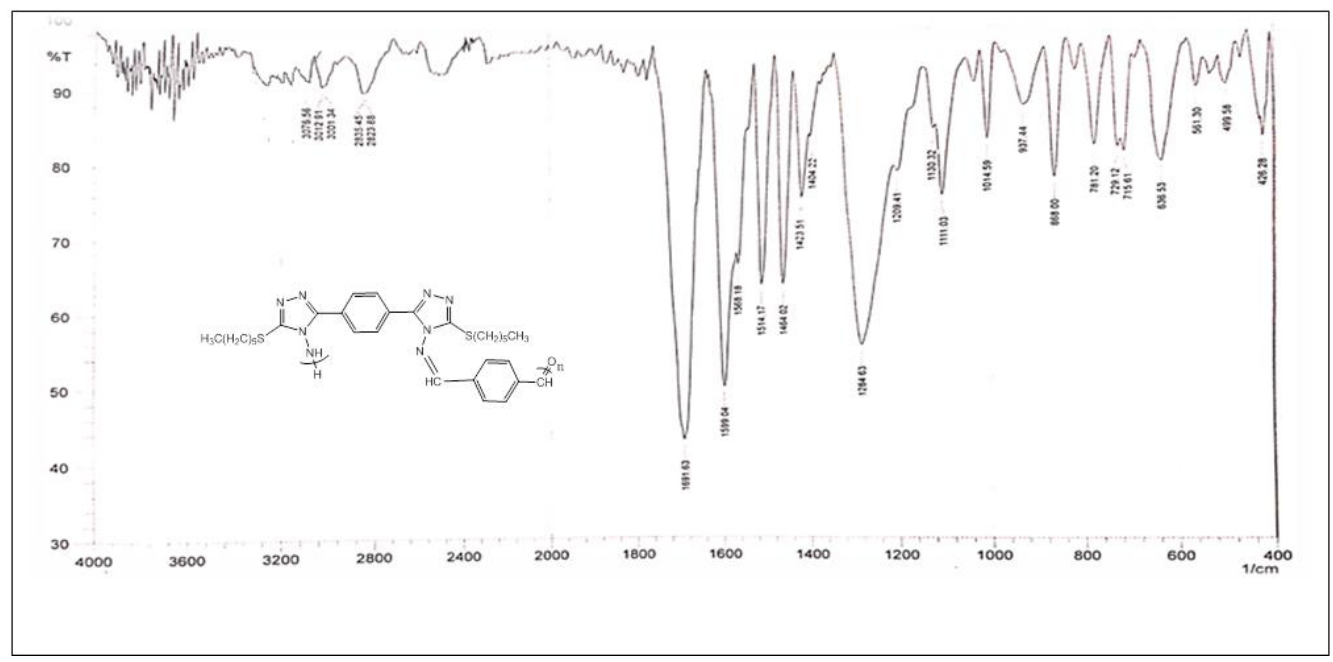

Figure (9): IR spectrum of polymer PVI

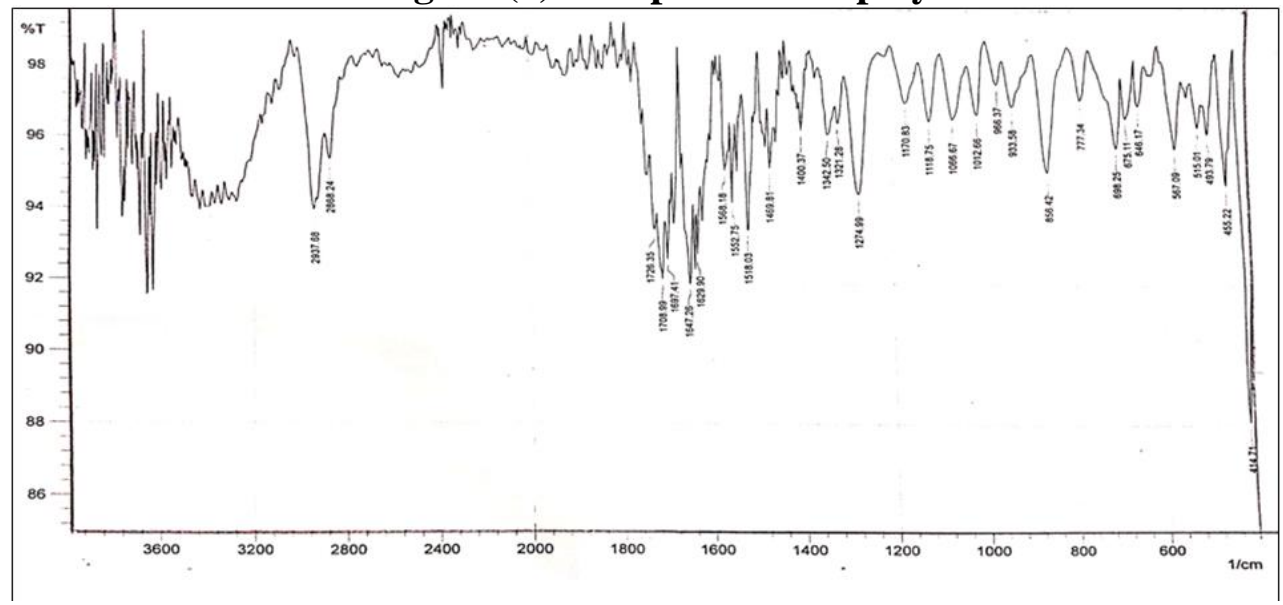

Figure (10): IR spectrum of polymer PVII

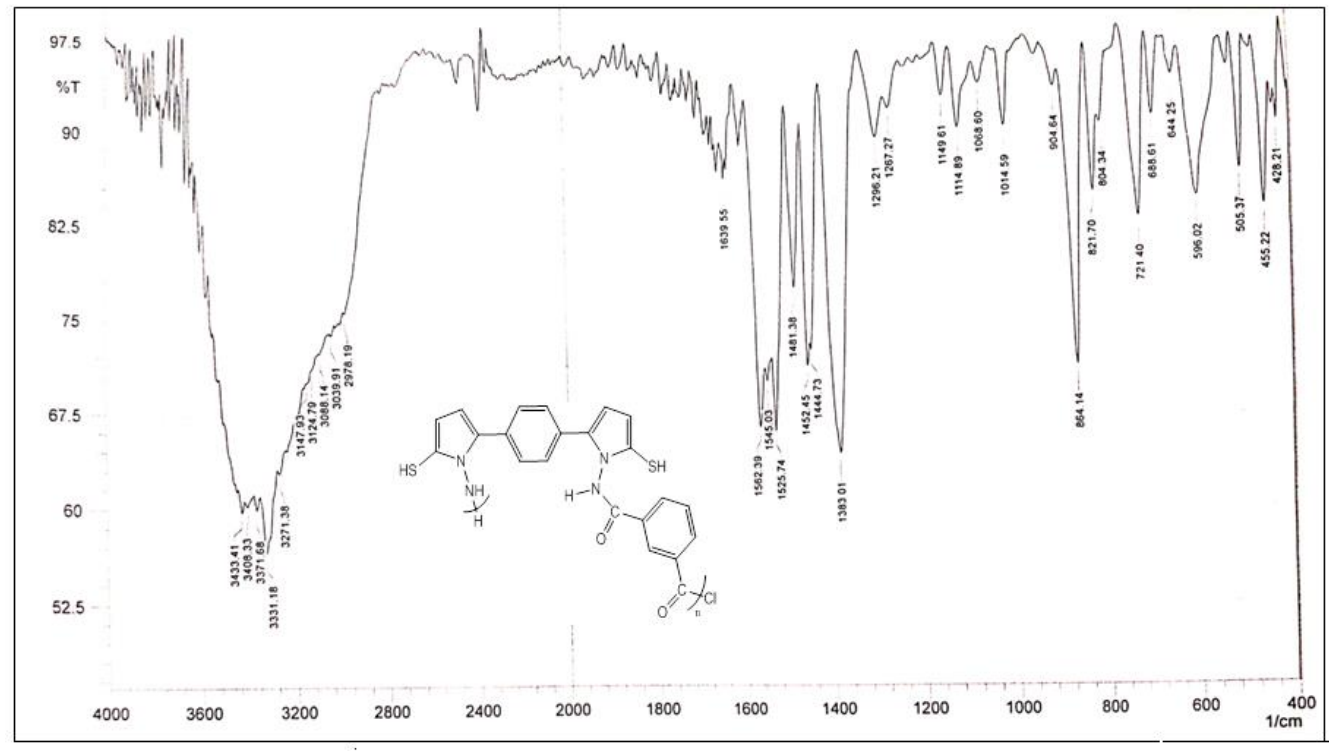

Figure (11): IR spectrum of polymer PVIII 